\title{
Effects of Melatonin and Flavonoid-Rich Fractions of Chromolaena odorata on the Alteration of Proinflammatory Cytokines and Nitric Oxide Induced by Aflatoxin B1 in the Gastric Mucosa of Wistar Rats
}

Adetayo Sadudeen Amid, ${ }^{1}$ Oludele Ayobami Makinde, ${ }^{2}$ and Fadeyemi Joseph Akinrinmade ${ }^{3}$

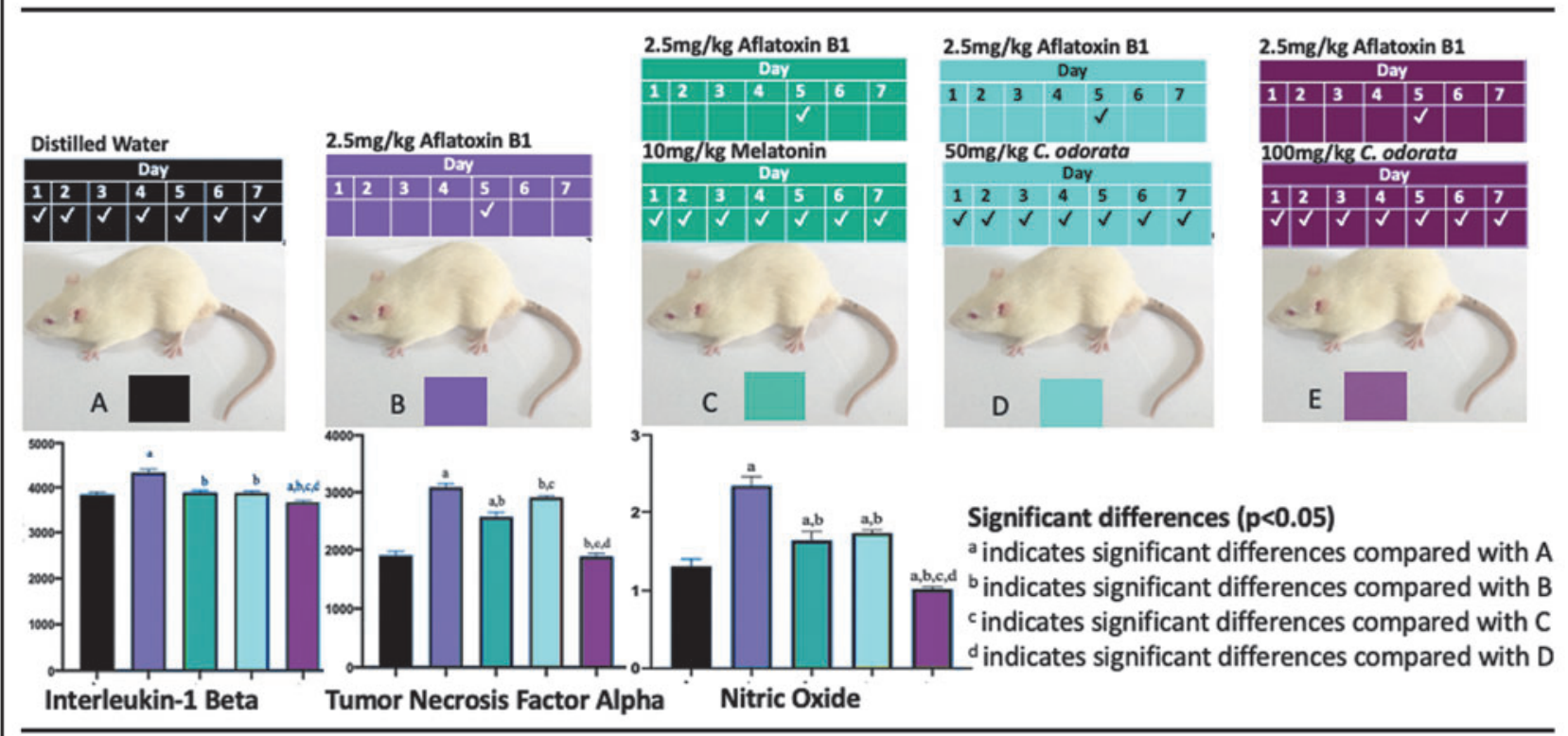

Conclusion: MEL and FRFC may be responsible for the prevention of increased gastric mucosal nitric oxide and inflammatory effects of proinflammatory cytokines induced by AFB1. (A)Control, (B) AFB1 only, (C) AFB1 + MEL, (D)AFB1+FRFC1, and (E) AFB1+FRFC2.
Reference: Adetayo Sadudeen Amid, Oludele Ayobami Makinde, and Fadeyemi Joseph Akinrinmade DOI: 10.1089/jir.2019.0101

Visual Abstract created by Adetayo Sadudeen Amid

\footnotetext{
${ }^{1}$ Department of Veterinary Surgery and Radiology, Faculty of Veterinary Medicine, University of Ilorin, Ilorin, Nigeria.

${ }^{2}$ Department of Veterinary Medicine and Surgery, College of Veterinary Medicine, Federal University of Agriculture, Abeokuta, Nigeria.

${ }^{3}$ Department of Veterinary Surgery and Radiology, Faculty of Veterinary Medicine, University of Ibadan, Ibadan, Nigeria.
} 
In this study, we investigated serum interleukin-1 beta (IL-1 $\beta$ ) and tumor necrosis factor alpha (TNF- $\alpha$ ) after ingestion of aflatoxin B1 (AFB1) in rats. We also studied the effects of nitric oxide (NO) on the stomach after consumption of AFB1. Therefore, we hypothesized that a standard anti-inflammatory agent-melatonin (MEL), and the flavonoid-rich fractions from Chromolaena odorata (FRFC) could counteract the deleterious effects of IL-1 $\beta$, TNF- $\alpha$, and NO after consumption of AFB1. Thirty-five Wistar rats $(211.86 \pm 27.23 \mathrm{~g})$ were randomly selected into 5 groups, with 7 rats in each group. Group A (control); all rats in groups B, C, D, and E received $2.5 \mathrm{mg} / \mathrm{kg}$ AFB1 each orally on day 5, whereas those of groups $\mathrm{C}, \mathrm{D}$, and $\mathrm{E}$ received oral administration of $10 \mathrm{mg} / \mathrm{kg} \mathrm{MEL}, 50 \mathrm{mg} / \mathrm{kg} \mathrm{FRFC}_{1}$, and $100 \mathrm{mg} / \mathrm{kg} \mathrm{FRFC}$, respectively, for 7 days. All of them were killed on the 8th day, $24 \mathrm{~h}$ after last treatment. Serum samples were analyzed for IL-1 $\beta$ and TNF- $\alpha$, whereas stomach tissue was evaluated for NO level. Significant $(P<0.5)$ increase in serum IL-1 $\beta$ and TNF- $\alpha$ in rats given AFB1 only was recorded when compared with those in the control group. Conversely, we observed significant reduction in serum IL- $1 \beta$ and TNF- $\alpha$ in all the groups that received MEL, FRFC 1 , and $\mathrm{FRFC}_{2}$ after pretreatment with AFB1 when compared with those that were given AFB1 only. In addition, there was a significant increase in NO in rats given AFB1 only when compared with control, whereas reduction in NO was significant in the groups $\mathrm{C}, \mathrm{D}$, and $\mathrm{E}$ that were given MEL, $\mathrm{FRFC}_{1}$, and $\mathrm{FRFC}_{2}$, respectively, when compared with AFB1 group. MEL and FRFC may be responsible for the prevention of increased gastric mucosal NO and inflammatory effects of proinflammatory cytokines induced by AFB1.

Keywords: Chromolaena odorata, aflatoxin B1, interleukin-1 beta, tumor necrosis factor alpha, nitric oxide, stomach

\section{Introduction}

$\mathrm{B}$ OTH ANIMAL FEEDS and foods for human consumption are practically unavoidably exposed to significant contamination risk by toxigenic fungi (Magan and Olsen 2004), which when consumed can cause acute or chronic toxicity in both animals and humans (Alshannaq and Yu 2017). In addition, consumption of animal-derived food products like eggs, milk, or meat, with appreciable residues of mycotoxin metabolites, poses public health concerns (Alshannaq and $\mathrm{Yu}$ 2017).

Mostly, mycotoxins are immunosuppressive causing cancer (Marroquín-Cardona and others 2014).

Aflatoxin B1 (AFB1), which predominates among aflatoxins is the most bio-hazardous metabolite of mycotoxins, and it is produced by a common mold-Aspergillus speciesthat ubiquitously grows on all food ingredients, particularly grains, peanuts, soybeans, milk products, poultry by-products, animal products, and groundnut cake.

Apart from causing acute toxicity, AFB1 is known to be cytotoxic, hepatotoxic, (Akinrinmade and others 2016), nephrotoxic, and neurotoxic to humans and animals (Peraica and others 1999).

Effects of AFB1 on inflammatory reactions have been researched. Evidences of acute inflammation consistent with significant elevation in serum proinflammatory cytokines are attributable to AFB1 administration in rats (Akinrinmade and others 2016). During inflammation, vasodilation is, to a large extent, produced by nitric oxide (NO)-dependent process (Tousoulis and others 2011).

Extracts of Chromolaena odorata ( $C$. odorata) have been researched (Akinmoladun and Ibukun, 2016) and reported to prevent gastrointestinal tissues from oxidative and inflammatory damages (Agag 2005; Bhargava and others 2013; Akinmoladun and Ibukun, 2016).

Melatonin (MEL) and flavonoid-rich fractions from C. odorata (FRFC) have been published to be partly involved in the amelioration of hepatic and intestinal lesions associated with AFB1 injury, through modulation of cytokines expression (Akinrinmade and others 2016). However, there are no reports of effects of MEL and FRFC on the alteration of proinflammatory cytokines and NO induced by AFB1 in the gastric mucosa of Wistar rats. Hence, the exigency of this research to investigate the bioavailability of serum proinflammatory cytokines (interleukin-1 beta [IL-1 $\beta$ ] and tumor necrosis factor alpha $[\mathrm{TNF}-\alpha]$ ) and gastric mucosal perfusion consistent with increased $\mathrm{NO}$ after ingestion of AFB1 in rats.

Therefore, we hypothesized that a standard anti-inflammatory agent, MEL and the FRFC, which has also been reported to possess anti-inflammatory property (Bekyarova and others 2012) could produce desirable effects on the alteration of proinflammatory cytokines and NO induced by AFB1 in the gastric mucosa of Wistar rats.

\section{Materials and Methods}

\section{Extraction of FRFC}

Collection of fresh leaves of $C$. odorata with voucher number UIH-22385 was carried out at the Botanical garden of University of Ibadan (Nigeria). The leaves were electrically blended into coarse power after they had been cleaned and air-dried at room temperature. This coarse power was then defatted in N-hexane and was allowed to be soaked in $70 \%$ ethanol in the ratio of $1 \mathrm{~g}$ defatted material to $50 \mathrm{~mL} 70 \%$ ethanol. Flavonoid fraction was then extracted by placing this mixture ( $1 \mathrm{~g}$ defatted material and $50 \mathrm{~mL} 70 \%$ ethanol) in an ultrasonic bath device, known as Supersonic X-3, Model DSD80A5QS, at room temperature for $1 \mathrm{~h}$. This method was reported by Zhu and others (2010), but with little modification, the ultrasonic fraction obtained was then filtered and the filtrate underwent rotary evaporation to obtain concentrated filtrate. This concentrated filtrate was dissolved in distilled water, ready to be administered to experimental animals.

\section{Chemicals}

Provision of AFB1 was made by Dr. Joseph Atehnkeng, International Institute of Tropical Agriculture (IITA) (Ibadan, 
Oyo State, Nigeria). MEL was purchased from Abcam Biochemicals (Cambridge, UK). Other chemicals used for the purpose of this experiment were commercially purchased from British Drug Houses (Poole, Dorset, UK) and they were of analytical grade.

\section{Experimental animals}

Thirty-five Wistar rats with mean body weight of $211.86 \pm 27.23 \mathrm{~g}$ were obtained from the University of Ibadan, Faculty of Veterinary Medicine Laboratory Animal Unit. They were housed in well-ventilated cage compartments with adequate space for exercise and were fed on commercial rat feed (Guinea feeds ${ }^{\circledR}$ ) and were given distilled water $\left(\mathrm{DH}_{2} \mathrm{O}\right)$ ad libitum. They were healthy based on clinical examination before commencement of the experiment and were approved by the Animal Care and Use Research Ethics Committee of the Faculty of Veterinary Medicine, University of Ibadan (approval no. UI-ACUREC/ App/2015/006).

All animals were allowed 14 days of acclimatization with natural photoperiod of $\sim 12$-hour light and 12-hour darkness daily. This protocol is consistent with the guidelines of the National Institutes of Health (NIH) guidelines for laboratory animal care and use.

\section{Experimental protocol}

The rats were chosen at random into 5 experimental groups (A, B, C, D, and E) with each group consisting of 7 rats. Table 1 provides the summary of grouping of experimental rats, dosages, routes, and duration of administrations of AFB1, MEL, and FRFC. All animals were killed on the 8th day, $24 \mathrm{~h}$ after last treatment (Akinrinmade and others 2016).

\section{Serum collection}

Retro-orbital venous plexus blood sample collection technique was performed (Van Herck and others 2001). This same technique of blood collection was performed in all the 35 rats in the same manner. The whole blood samples collected were allowed to coagulate for $30 \mathrm{~min}$. They were then centrifuged at $3,000 \mathrm{~g}$ for $10 \mathrm{~min}$ under refrigeration at $4^{\circ} \mathrm{C}$. The resulting supernatant after centrifugation was immediately transferred into a clean polypropylene sample tube

Table 1. Summary of Experimental Protocol

Sample

Group Treatments Dosage Route Duration collection

\begin{tabular}{llllll}
\hline A & $\mathrm{DH}_{2} \mathrm{O}$ & Ad libitum & Oral & 7 days & Day 8 \\
$\mathrm{~B}$ & $\mathrm{AFB} 1$ & $2.5 \mathrm{mg} / \mathrm{kg}$ & Oral & 5 th day & Day 8 \\
$\mathrm{C}$ & AFB1 & $2.5 \mathrm{mg} / \mathrm{kg}$ & Oral & 5 th day & Day 8 \\
& $\mathrm{Mel}$ & $10 \mathrm{mg} / \mathrm{kg}$ & Oral & 7 days & \\
$\mathrm{D}$ & $\mathrm{AFB1}$ & $2.5 \mathrm{mg} / \mathrm{kg}$ & Oral & 5 th day & Day 8 \\
& $\mathrm{FRFC}_{1}$ & $50 \mathrm{mg} / \mathrm{kg}$ & Oral & 7 days & \\
$\mathrm{E}$ & $\mathrm{AFB1}$ & $2.5 \mathrm{mg} / \mathrm{kg}$ & Oral & 5 th day & Day 8 \\
& $\mathrm{FRFC}_{2}$ & $100 \mathrm{mg} / \mathrm{kg}$ & Oral & 7 days & \\
\hline
\end{tabular}

Group A, control; group $\mathrm{B}, \mathrm{AFB} 1$ only; group $\mathrm{C}, \mathrm{AFB} 1+\mathrm{MEL}$; group D, AFB1+FRFC 1 ; group $\mathrm{E}, \mathrm{AFB} 1+\mathrm{FRFC}_{2}$.

$\mathrm{AFB} 1$, aflatoxin $\mathrm{B} 1 ; \mathrm{DH}_{2} \mathrm{O}$, distilled water; $\mathrm{FRFC}_{1}$ and $\mathrm{FRFC}_{2}$, $50 \mathrm{mg} / \mathrm{kg}$ and $100 \mathrm{mg} / \mathrm{kg}$ flavonoid-rich fractions from Chromolaena odorata, respectively; MEL, melatonin. using a Pasteur Pipette. These serum samples were stored at $-20^{\circ} \mathrm{C}$.

\section{Enzyme linked immunosorbent assay}

IL-1 $\beta$ and TNF- $\alpha$ enzyme-linked immunosorbent assay (ELISA) test kits (Abcam Biochemicals) are in vitro ELISA for the quantitative measurement of rat IL- $1 \beta$ and TNF- $\alpha$ in the serum, respectively. The assay was carried out in accordance with the manufacturer's instructions.

\section{Biochemical analysis}

The stomach tissue samples collected for biochemical assay were quickly rinsed in ice-cold $1.15 \% \mathrm{KCl}$ after which they were blotted and then weighed. A phosphate buffer solution of $0.1 \mathrm{M}$ and $\mathrm{pH} 7.4$ in 4 volumes was added to all the stomach tissues stored at $-20^{\circ} \mathrm{C}$. They were then homogenized and centrifuged at 10,000 $\mathrm{g}$ under refrigeration at $4^{\circ} \mathrm{C}$ for $10 \mathrm{~min}$. The postmitochondrial fractions of the stomach tissue were analyzed to determine activity of NO.

\section{Statistical analysis}

All data were statistically calculated and therefore, expressed as mean \pm standard deviation. Student's $t$-test was used to determine if 2 groups of data were significantly different from each other. One-way analysis of variance (ANOVA) consistent with Turkey's post hoc test was also used to calculate statistical significance within all the groups. $P<0.05$ was considered as statistical significance (Hedges and Rhoads 2010) for both statistical tests used. GraphPad Prism 8 was used to plot the graphs with error bars.

\section{Results}

\section{Effects of MEL and FRFC on the alteration of proinflammatory cytokines induced by AFB1}

Levels of serum proinflammatory cytokines, IL-1 $\beta$ and TNF- $\alpha$, are given in Figs. 1 and 2, respectively. The levels of IL- $1 \beta$ and TNF- $\alpha$ in the serum samples of rats that were given AFB1 only increased significantly $(P<0.05)$ when compared with the control groups. It was also observed that there was significant reduction in levels of IL- $1 \beta$ and TNF- $\alpha$ in the serum samples of all the rats in the groups $\mathrm{C}, \mathrm{D}$, and $\mathrm{E}$ that were given AFB1 in combination with MEL, $\mathrm{FRFC}_{1}$, and FRFC $_{2}$, respectively, when compared with groups that received AFB1 only. More so, there was a significant reduction in IL- $1 \beta$ and TNF- $\alpha$ in group $E$ that received $100 \mathrm{mg} / \mathrm{kg}$ FRFC $_{2}$ when it was compared with groups $\mathrm{C}$ and $\mathrm{D}$ that were given MEL and $50 \mathrm{mg} / \mathrm{kg} \mathrm{FRFC}_{1}$, respectively.

\section{Effects of MEL and FRFC on the alteration of NO consistent with increased perfusion of stomach induced by AFB1}

In this research as given in Fig. 3, there was a significant $(P<0.05)$ increase in NO in the stomach of all the rats that received AFB1 only when compared with the control group. Meanwhile, stomach samples of rats in groups $\mathrm{C}, \mathrm{D}$, and $\mathrm{E}$ that received $\mathrm{AFB} 1$ in combination with MEL, $\mathrm{FRFC}_{1}$, and 


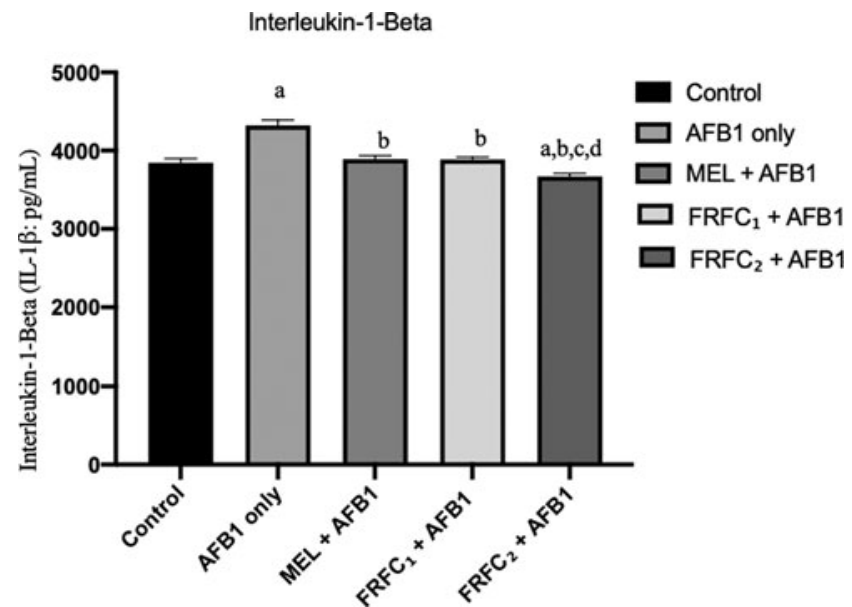

FIG. 1. Effects of MEL, FRFC 1 , and $\mathrm{FRFC}_{2}$ on the alteration of IL-1 $\beta$ induced by AFB1. Values are given as mean \pm SD. "a" indicates significant differences $(P<0.05)$ compared with control; "b" indicates significant differences compared with AFB1 group; "c" indicates significant differences compared with MEL+AFB1 group; "d" indicates significant differences compared with $\mathrm{FRFC}_{1}+\mathrm{AFB} 1$ group. AFB1, aflatoxin B1 $(2.5 \mathrm{mg} / \mathrm{kg}) ; \mathrm{FRFC}_{1}$, flavonoid-rich fraction from Chromolaena odorata $(50 \mathrm{mg} / \mathrm{kg}) ; \mathrm{FRFC}_{2}$, flavonoidrich fraction from Chromolaena odorata $(100 \mathrm{mg} / \mathrm{kg}) ; \mathrm{IL}-1 \beta$, interleukin-1 beta; MEL, melatonin $(10 \mathrm{mg} / \mathrm{kg})$; SD, standard deviation.

$\mathrm{FRFC}_{2}$, respectively, were observed to demonstrate significant reduction in the level of $\mathrm{NO}$ when compared with the group that was given AFB1 only. In addition, as the dose of FRFC was increased from 50 to $100 \mathrm{mg} / \mathrm{kg}$, there was a significant reduction in the level of $\mathrm{NO}$ in group $\mathrm{E}$ that received $100 \mathrm{mg} / \mathrm{kg} \mathrm{FRFC}_{2}$ when compared with group D that received $50 \mathrm{mg} / \mathrm{kg} \mathrm{FRFC}_{1}$.

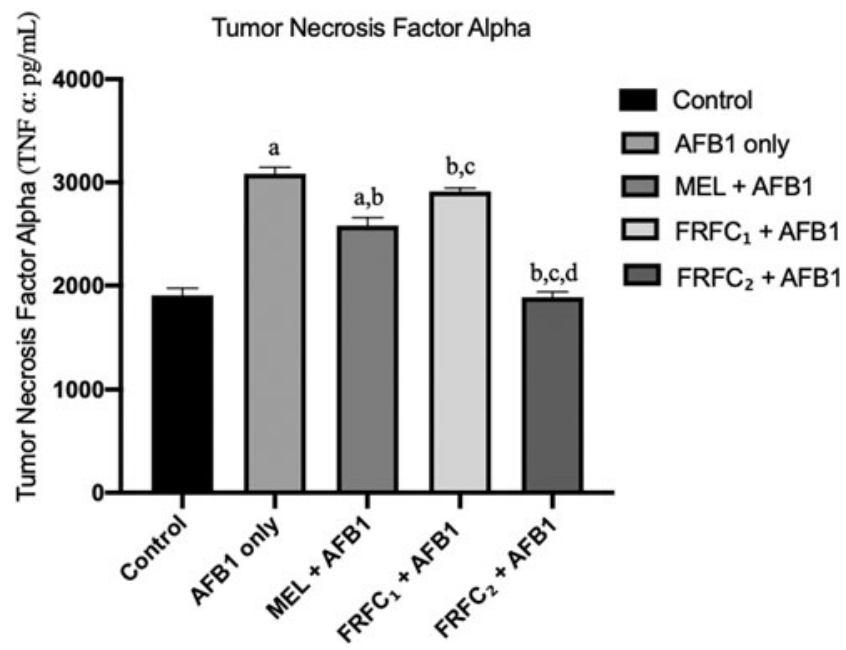

FIG. 2. Effects of MEL, FRFC 1 , and FRFC 2 on the alteration of TNF- $\alpha$ induced by AFB1. Values are given as mean \pm SD. "a" indicates significant differences $(P<0.05)$ compared with control; " $b$ " indicates significant differences compared with AFB1 group; "c" indicates significant differences compared with MEL+AFB1 group; "d" indicates significant differences compared with $\mathrm{FRFC}_{1}+\mathrm{AFB} 1$ group. TNF- $\alpha$, tumor necrosis factor alpha.

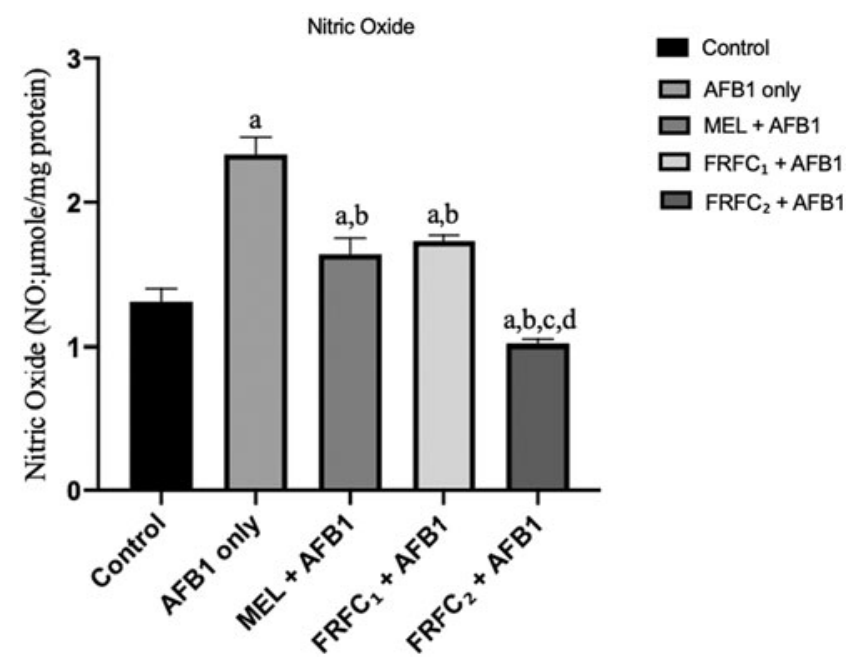

FIG. 3. Effects of MEL, FRFC 1 , and $\mathrm{FRFC}_{2}$ on the alteration of nitric oxide consistent with increased perfusion of stomach induced by AFB1. Values are given as mean \pm SD. "a" indicates significant differences $(P<0.05)$ compared with control; "b" indicates significant differences compared with AFB1 group; "c"' indicates significant differences compared with MEL+AFB1 group; "d" indicates significant differences compared with $\mathrm{FRFC}_{1}+\mathrm{AFB} 1$ group.

\section{Discussion}

The roles of inflammatory processes in acute and chronic diseases cannot be underrated (Kurlan 2012). Although inflammatory reactions can serve as the major defense mechanism against injurious agents, it can also be responsible for the emergence of several disease conditions such as cancer and granulomatous diseases (Kurlan 2012). An increase in bioavailability of proinflammatory signaling molecules in circulation has been described as a contributory factor to various life-threatening diseases like cancer and atherosclerosis (Scarpioni 2016). A group of polypeptides, referred to as cytokines, are a variety of soluble factors responsible for mediation of inflammatory reactions. These cytokines mediate acute and chronic inflammatory reactions (Feghali and Wright 1997). IL-1 $\beta$ and TNF- $\alpha$ are proinflammatory cytokines (Polińska and others 2009) known to be involved in acute phase inflammatory processes. Others are IL-6, IL-11, IL-8, granulocyte colony stimulating factor, and granulocyte-macrophage colony-stimulating factor (Feghali and Wright 1997).

Elevation in mucosal and systemic concentrations of proinflammatory cytokines has been reported in inflammatory bowel disease (Polińska and others 2009). Proinflammatory cytokines have also been implicated in the occurrence and the progression of hepatocellular damage induced by AFB1 (Qian and others 2014). IL-1 $\beta$ has been described as the most potent endogenous pyrogens in humans and animals (Dinarello 1996). A significant elevation in serum IL-1 $\beta$ after administration of AFB 1 consistent with acute inflammatory response has been reported (Akinrinmade and others 2016).

In this study, it was observed that there was a significant elevation in serum bioavailability level of IL-1 $\beta$ in rats that received AFB1 only. This outcome is in consonance with the published reports of Akinrinmade and others (2016). 
The involvement of TNF- $\alpha$ in acute phase reaction has been reported (Nakazawa 2010). This TNF- $\alpha$ has been implicated in the development DNA damage of cells and tissue structural design important for survival of tumor cells and metastasis (Balkwill 2002). AFB1, when given to rats, resulted in overexpression of proinflammatory cytokineTNF- $\alpha$ (Singh and others 2014; Koohi and others 2017). In this study, when AFB1 was given orally to rats, there was a significant increase in the serum level of TNF- $\alpha$, which is in accordance with the reports of Singh and others (2014) and Koohi and others (2017).

NO, a proinflammatory mediator, which when over produced in abnormal conditions, is responsible for the induction of inflammatory reaction and pathogenesis of inflammatory disorders of the gut, lungs, and joint (Sharma and others 2007). Through the formation of highly reactive peroxynitrite, NO is known to increase cellular damage (Guix and others 2005). Meik and others (2001), in their study, reported a significant increase in NO in liver tissues after administration of AFB1. In this study, it was also recorded that there was a significant increase in level of NO in the stomach of rats that were given AFB1 only.

These increases in levels of proinflammatory cytokines (IL-1 $\beta$ and TNF- $\alpha$ ) and NO after administration of AFB1 only is consistent with the earlier reports of inflammatory effects of AFB1 (Meik and others 2001; Singh and others 2014; Akinrinmade and others 2016; Koohi and others 2017) on the stomach mucosa.

An important antioxidant hormone known as MEL, which is naturally synthesized and secreted by the pineal gland and widely distributed (Vasicek and others 2005) is responsible for modulation of proinflammatory cytokines, and antiinflammatory cytokines in different pathological and physiologic conditions (Favero and others 2017). Patients under critical health conditions have demonstrated reduced melanin secretion levels both in nocturnal peaks and basal daytime (Mistraletti and others 2010).

Beneficial therapeutic values of exogenous MEL administration have been evaluated and it has been reported to be valuable in the treatment of ulcerative colitis, an inflammatory disease of gastrointestinal tract (Carrascal and others 2018). An 15\% absolute bioavailability of MEL has been assayed after $4 \mathrm{mg}$ oral dosage in humans (Demuro and others 2000). In mice, MEL administration resulted in inhibition of tumor growth and blockage of tumor angiogenesis. In addition, inducible NO synthase activation was prevented by MEL, thereby decreasing production of NO. In rats, MEL pretreatment resulted in the reduction of proinflammatory cytokines IL-1 $\beta$ and TNF- $\alpha$ (Carrasco and others 2013).

In this study, there was a significant reduction in proinflammatory cytokines (IL- $1 \beta$ and $\mathrm{TNF}-\alpha$ ) and NO after administration of MEL, after being pretreated with AFB1. This might be owing to the anti-inflammatory activities of MEL as earlier reported by Carrascal and others (2018) to counteract the inflammatory effects of AFB1 (Meik and others 2001; Singh and others 2014; Akinrinmade and others 2016; Koohi and others 2017) on the stomach.

Numerous extracts of medicinal plants have been researched as potent modulators of proinflammatory signaling molecules used as part of novel treatment modalities of so many disease conditions. An in-depth review of literature has revealed that C. odorata possesses antioxidant, anti-inflammatory, and wound healing properties (Chakraborty and others 2011;
Vaisakh and Pandey 2012). In rats, administration of aqueous extract of $C$. odorata resulted in anti-inflammation and wound healing, justifying its traditional uses as medicinal plant (Owoyele and others 2005). Its phytochemical analysis revealed that its components are not limited to phenolics, saponins, tannins, alkaloids and terpenoids, eupolin, chromomoric acid, quercetagetin, and quercetin, but also include flavonoids and flavanone, all of which are responsible for its remedial properties (Sirinthipaporn and Jiraungkoorskul 2017). In another research, it was also concluded that overall, $C$. odorata was a good NO scavenger (Alisi and Onyeze 2008). The finding that FRFC modulated expression of Glucagon-like peptide-1, might account for its antidiabetic potency. A decrease in the expression of pro-inflammatory signaling molecules in the circulation has been reported to be associated with reduction in attack by numerous disease conditions (Dinarello 2000). Flavonoid-rich extract of $C$. odorata was reported to modulate expression of cytokines that might have, in part, resulted in the amelioration of intestinal lesions caused by AFB1 (Akinrinmade and others 2016). In this study, there was a significant reduction in the levels of pro-inflammatory cytokines (IL-1 $\beta$ and TNF- $\alpha$ ) and NO after administration of $50 \mathrm{mg} / \mathrm{kg}$ FRFC after being pretreated with AFB1. This is in accordance with the reports of Akinrinmade and others (2016). The significant reduction in the levels of proinflammatory cytokines (IL-1 $\beta$ and TNF- $\alpha$ ) and NO was further decreased, significantly, when the dosage of FRFC was increased to $100 \mathrm{mg} / \mathrm{kg}$. The reduction in proinflammatory cytokines may be because of the anti-inflammatory properties of $C$. odorata (Chakraborty and others 2011; Vaisakh and Pandey 2012), whereas the significant reduction in the level of NO maybe as a result of its antioxidant property (Alisi and Onyeze 2008).

\section{Conclusion}

The effects of MEL and FRFC, seen as reduction in the levels of proinflammatory cytokines and NO, may be responsible for the prevention of inflammatory effects of proinflammatory cytokines and decrease in gastric mucosal NO, both induced by AFB1. We therefore, suggest a furtherance in research of this methodology for better understanding of gastric mucosal protection against AFB1, as it might be a step in the right direction.

\section{Acknowledgments}

The authors thank Joseph Atehnkeng of the Aflasafe Laboratory, International Institute of Tropical Agriculture (IITA) (Ibadan, Oyo State, Nigeria), who provided AFB1 for the purpose of this experiment.

\section{Author Disclosure Statement}

No competing financial interests exist.

\section{Funding Information}

No funding was received for this article.

\section{References}

Agag BI. 2005. Mycotoxins in foods and feeds 5-Trichothecenes A-T-2 Toxin. Ass Univ Bull Environ Res 8:107-124.

Akinmoladun AC, Ibukun EO. 2016. Phytochemical constituents and antioxidant properties of extracts from the leaves of 
Chromolaena odorata Phytochemical constituents and antioxidant properties of extracts from the leaves of Chromolaena odorata. Sci Res Essay 2(6):191-194.

Akinrinmade FJ, Akinrinde S, Amid A. 2016. Changes in serum cytokine levels, hepatic and intestinal morphology in aflatoxin B1-induced injury: modulatory roles of melatonin and flavonoid-rich fractions from Chromolena odorata. Mycotoxin Res 32(2):53-60.

Alisi CS, Onyeze GOC. 2008. Nitric oxide scavenging ability of ethyl acetate fraction of methanolic leaf extracts of Chromolaena odorata (Linn.). Afr J Biochem Res 2(7): 147.

Alshannaq A, Yu JH. 2017. Occurrence, toxicity, and analysis of major mycotoxins in food. Int J Environ Res Public Health 14(6):632.

Balkwill F. 2002. Tumor necrosis factor or tumor promoting factor? Cytokine Growth Factor Rev 13(2):135-141.

Bekyarova G, Apostolova M, Kotzev I. 2012. Melatonin protection against burn-induced hepatic injury by down-regulation of nuclear factor kappa B activation. Int J Immunopathol Pharmacol 25(3):591-596.

Bhargava D, Mondal CK, Shivapuri JN, Mondal S, Kar S, National. 2013. Antioxidant properties of the leaves of Chromolaena odorata Linn. J Instit Med 35(1):53-56.

Carrascal L, Nunez-Abades P, Ayala A, Cano M. 2018. Role of melatonin in the inflammatory process and its therapeutic potential. Curr Pharm Des 24(14):1563-1588.

Carrasco C, Marchena AM, Holguín-Arévalo MS, MartínPartido G, Rodríguez AB, Paredes SD, Pariente JA. 2013. Anti-inflammatory effects of melatonin in a rat model of caerulein-induced acute pancreatitis. Cell Biochem Funct 31(7):585-590.

Chakraborty, Anup k, Rambhade S, Patil, Umesh K. 2011. Chromolaena odorata (L.). An overview. J Pharm Res 4(3): 573-576.

Demuro RL, Nafziger AN, Blask DE, Menhinick AM, Bertino JS. 2000. The absolute bioavailability of oral melatonin. J Clin Pharmacol 40(7):781-784.

Dinarello CA. 1996. Biologic basis for interleukin-1 in disease. Blood 87:2095-2147.

Dinarello CA. 2000. Proinflammatory cytokines. Chest 118(2): 503-508.

Favero G, Franceschetti L, Bonomini F, Rodella LF, Rezzani R. 2017. Melatonin as an anti-inflammatory agent modulating inflammasome activation. Int J Endocrinol 2017:1-13.

Feghali CA, Wright TM. 1997. Cytokines in acute and chronic inflammation. Front Biosci 2:12-26.

Guix FX, Uribesalgo I, Coma M, Muñoz FJ. 2005. The physiology and pathophysiology of nitric oxide in the brain. Prog Neurobiol 76(2):126-152.

Hedges LV, Rhoads C. 2010. Statistical power analysis. In: Peterson P, Baker E, McGraw B (Eds.). International Encyclopedia of Education. Amsterdam, Netherlands: Elsevier, pp. 436-443.

Koohi MK, Ghazi-Khansari M, Hayati F, Staji H, Keywanloo M, Shahroozian E. 2017. Role of TNF- $\alpha$ in aflatoxin B-1 induced hepatic toxicity in isolated perfused rat liver model. Acta Med Iran 55(7):416-421.

Kurlan R. 2012. Inflammation. In: Donner R (Ed.). Parkinson's Disease, 2nd Ed, vol. 88. Amsterdam, Netherlands: Elsevier, pp. 69-132.

Magan N, Olsen M. 2004. Mycotoxins in food: detection and control. In: Mycotoxins in food: detection and control, vol. 114, pp. 205-239.
Marroquín-Cardona AG, Johnson NM, Phillips TD, Hayes AW. 2014. Mycotoxins in a changing global environment-a review. Food Chem Toxicol 69:220-230.

Meik ARMA, Abdel-Ghaffar SK, El-Gibaly I. 2001. Aflatoxin B1 induces apoptosis in rat liver: protective effect of melatonin. Neuroendocrinol Lett 22(6):417-426.

Mistraletti G, Sabbatini G, Taverna M, Figini MA, Umbrello M, Magni P, Iapichino G. 2010. Pharmacokinetics of orally administered melatonin in critically ill patients. J Pineal Res 48(2):142-147.

Nakazawa T. 2010. Tumor necrosis factor $\alpha$. Jpn J Clin Ophthalmol 51:903-906.

Owoyele VB, Adediji JO, Soladoye AO. 2005. Antiinflammatory activity of aqueous leaf extract of Chromolaena odorata. Inflammopharmacology 13(5-6):479-484.

Peraica M, Radić B, Lucić A, Pavlović M. 1999. Toxic effects of mycotoxins in humans. Bull World Health Organ 77(9):754-766.

Polińska B, Matowicka-Karna J, Kemona H. 2009. The cytokines in inflammatory bowel disease. Postep Hig Med Dośw (Online) 63:389-394.

Qian G, Tang L, Guo X, Wang F, Massey ME, Su J, Wang JS. 2014. Aflatoxin B1modulates the expression of phenotypic markers and cytokines by splenic lymphocytes of male F344 rats. J Appl Toxicol 34(3):241-249.

Scarpioni R. 2016. Secondary amyloidosis in autoinflammatory diseases and the role of inflammation in renal damage. World JNephrol 5(1):66-75.

Sharma JN, Al-Omran A, Parvathy SS. 2007. Role of nitric oxide in inflammatory diseases. Inflammopharmacology 15(6):252259.

Singh KB, Maurya BK, Trigun SK. 2014. Activation of oxidative stress and inflammatory factors could account for histopathological progression of aflatoxin-B1 induced hepatocarcinogenesis in rat. Mol Cell Biochem 401(1-2):185-196.

Sirinthipaporn A, Jiraungkoorskul W. 2017. Wound healing property review of siam weed, Chromolaena odorata. Pharmacogn Rev 11(21):35-38.

Tousoulis D, Kampoli AM, Tentolouris Nikolaos Papageorgiou C, Stefanadis C. 2011. The role of nitric oxide on endothelial function. Curr Vasc Pharmacol 10(1):4-18.

Vaisakh MN, Pandey A. 2012. The invasive weed with healing properties: a review on Chromolaena odorata. Int J Pharm Sci 3(1):80-83.

van Herck H, Baumans V, Brandt CJWM, Boere HAG, Hesp APM, van Lith HA, Beynen AC. 2001. Blood sampling from the retro-orbital plexus, the saphenous vein and the tail vein in rats: comparative effects on selected behavioural and blood variables. Lab Anim 35(2):131-139.

Vasicek CA, Malpaux B, Fleming PA, Bennett NC. 2005. Melatonin secretion in the Mashona mole-rat, Cryptomys darlingiinfluence of light on rhythmicity. Physiol Behav 83(5):689-697.

$$
\begin{array}{r}
\text { Address correspondence to: } \\
\text { Dr. Adetayo Sadudeen Amid } \\
\text { Department of Veterinary Surgery and Radiology } \\
\text { Faculty of Veterinary Medicine } \\
\text { University of Ilorin } \\
\text { Ilorin 23431 } \\
\text { Nigeria }
\end{array}
$$

E-mail: amidadetayo@yahoo.com or amid.sa@unilorin.edu.ng

Received 23 June 2019/Accepted 14 January 2020 